\title{
Lipid Profile and Electrolyte Imbalance are Associated with Diabetic Retinopathy in Bangladeshi Population
}

\author{
Md. Golam Kabir ${ }^{1 *}$, Daniel Hossain ${ }^{2}$, R M Mazumdar ${ }^{3}$, Suman Mohajan $^{4}$, Monsor Rahman ${ }^{5}$ \\ ${ }^{1}$ Department of Biochemistry and Molecular Biology, University of Chittagong, \\ Chittagong, Bangladesh. \\ ${ }^{2}$ Department of Biochemistry and Molecular Biology, University of Chittagong, \\ Chittagong, Bangladesh. \\ ${ }^{3}$ Bangladesh Council of Scientific and Industrial Research (BCSIR), \\ Dhaka, Bangladesh. \\ ${ }^{4}$ Bangladesh Council of Scientific and Industrial Research (BCSIR), \\ Dhaka, Bangladesh. \\ ${ }^{5}$ Department of Chemistry, Nagarpur Government College, \\ Tangail, Bangladesh. \\ ${ }^{\star}$ Corresponding author's email: Kabir [AT] cu.ac.bd
}

\begin{abstract}
----
Background: Diabetic retinopathy (DR) is a micro-vascular complication which is the main cause of blindness among people with Diabetes Mellitus. Identification and mitigation of the risk factors associated with DR will help to reduce the visual disability in diabetic subjects.

Aims and objective: The study has been undertaken to explore the association of lipids profile and electrolytes with the diabetic retinopathy in Bangladeshi type 2 diabetic subjects.

Material and methods: In the present study, 63 people diabetic with retinopathy $(D R)$ and 80 people diabetic without retinopathy (DWR) were studied along with 92 healthy controls without family history diabetes and prediabetes. Anthropometric parameters, glucose, triglycerides, total cholesterol, high-density lipoprotein, low-density lipoprotein, glycosylated haemoglobin ( $\mathrm{HbAlc}$ ) and electrolytes $\mathrm{Na}^{+}, \mathrm{K}^{+}, \mathrm{Cl}, \mathrm{HCO}_{3}^{-}$were measured by standard methods.

Results: HbA1c of DWR group and DR group were $8.60 \pm 1.17$ and $11.80 \pm 1.63$ respectively. Total cholesterol, highdensity lipoprotein cholesterol (HDL-c), low-density lipoprotein cholesterol (LDL-c) were significantly higher $(p<0.001)$ in both DWR and DR group compared to the healthy control. Triglyceride was significantly $(p<0.001)$ higher in the DR group but no difference was found in DWR compared to the control group. $\mathrm{K}^{+}$was significantly increased in the DR group. $\mathrm{Na}^{+}, \mathrm{Cl}, \mathrm{HCO}_{3}{ }^{-}$were significantly decreased in the DR group compared to control group.

Conclusion: These results indicate that diabetic retinopathy patients exhibit dyslipidemia and electrolyte imbalance. Hypertriglyceridemia along with electrolyte imbalance is one the major risk factors toward the progression of diabetic retinopathy.
\end{abstract}

Keywords-Lipid profile, HbA1c, Electrolytes, Diabetic retinopathy. 


\section{INTRODUCTION}

Diabetic retinopathy (DR) is a vascular disorder that affects the microvasculature of retina. Half of the diabetes mellitus affected populations have some degree of $\mathrm{DR}^{1}$. DR is a complication of diabetes mellitus that and is one of the leading causes of acquired blindness in adults. Patients with diabetes for more than 20 years duration are likely to be affected by DR with a chance of losing sight ${ }^{2}$.

There are many factors related to the development and progression of diabetic retinopathy. Retinopathy in diabetic patients depends on carbohydrate metabolism as well as on other factors like poor diabetes control, dyslipidemia, insulindependent diabetes, hypertension, alcoholism, pregnancy, anemia, hypomagnesemia etc. ${ }^{5-13}$. However, it is possible to determine risk factors related to the development of retinopathy ${ }^{4}$. Duration of diabetes and degree of hyperglycemia have been found to play central role in DR, but maintaining only glucose level does not prevent the development of DR. Thus, other confounding factors related to the diabetes are postulated to have a causal role. Some pathological mechanisms for diabetes to retinopathy progression have been proposed. Although many of the risk factors of DR have been identified but role of these factors is still confusing.

Diabetic dyslipidemia characterized by elevated serum total cholesterol (TC), triglycerides (TG), low-density lipoproteins cholesterol (LDL-C) and high-density lipoproteins cholesterol (HDL-C) has been proposed as possible risk factors for $\mathrm{DR}^{14,15}$. It was also reported that local productions of reactive carbonyl species by the peroxidation of lipids in lipoproteins in the vascular wall mediate recruitment of macrophages, cellular activation, and proliferation. Lipoxidation end-products cause chemical modification of vascular proteins which affect both the structure and function of the vascular wall ${ }^{16}$. Accordingly, it was proposed that hyperlipidemia might contribute to DR by endothelial dysfunction and breakdown of the blood-retinal barrier causes serum lipids and lipoproteins exudation ${ }^{17}$.

Electrolytes perform a significant role in several body mechanisms, like acid-base balance, membrane potential, muscle contraction, nerve conduction, and control of body fluid ${ }^{18}$. Disturbance in electrolytes homeostasis may lead to physiologic disorders. Insulin has been shown to activate $\mathrm{Na}+\mathrm{K}+-\mathrm{ATPase}$ enzyme. Therefore, low serum insulin level reduces the enzyme with deregulation of $\mathrm{Na}+\mathrm{K}+$ pump that results in impairment of $\mathrm{Na}+$ and $\mathrm{K}+$ transport in and out of the cells, glucose transport also impaired with the defect of $\mathrm{Na}+\mathrm{K}+$ pump. Hyperglycemia in diabetes mellitus causes glucose-induced osmotic diuresis with resultant loss of body fluids and electrolytes ${ }^{18}$. Several studies reported that evaluated level of electrolytes is associated with hyperglycemia ${ }^{19,20}$. A study by Javaid et al (2007), demonstrated that blood sugar lowering drugs causes electrolyte imbalance by lowering sodium and increasing potassium ${ }^{20}$. Another study by Yasmin et al (2006), found lower levels of all electrolytes i.e. sodium, potassium, chloride, calcium, magnesium, and phosphorus $^{21}$.

The risk factors for the development of DR have been established based on mainly from European and US studies. So far, no study had been done to explore the association of serum lipid and electrolytes with retinopathy in Bangladeshi type 2 Diabetic subjects as it is well established that racial variations are also a confounding factor of diabetic retinopathy. Based on the above context, the present study was designed to investigate association of lipid profile and electrolyte imbalance with diabetic retinopathy in type 2 diabetic Bangladeshi population.

\section{MATERIALS AND METHODS}

This cross-sectional observational study was conducted in Chittagong Diabetic Hospital, Chittagong, Bangladesh. A group of 63 diabetic with retinopathy (DR) people and 80 diabetic without retinopathy (DWR) people were included in this study. In the case of diabetic subjects with or without retinopathy, they were selected from the ophthalmology department at Diabetic Hospital in Chittagong. There was no specific predilection for race, religion, and socio-economic status. Ninety-two age sex and BMI matched healthy subjects without a family history of diabetes were recruited as controls from the friend circle as considering the same socio-economic status. Written consent was obtained from all the volunteers; clinical examinations were undertaken by a registered physician using a predesigned questionnaire. Patients with serious comorbid diseases (infection, stroke, myocardial infarction, major surgery, malabsorption, etc.) and history of using drugs significantly affecting glucose metabolism (glucocorticoids, oral contraceptives, containing levonorgestrel or high-dose estrogen, phenytoin, high-dose thiazide diuretics, etc.) were excluded from the study. Anthropometric measurements were taken using standard methods. Subjects were requested to come on a prescheduled morning after overnight fasting for the fasting blood sample; subjects were then given $75 \mathrm{gm}$ of anhydrous glucose, dissolved in 250 $\mathrm{mL}$ water or breakfast for the diabetic subjects. Blood was taken venipuncture at fasting condition, and $2 \mathrm{~h}$ post glucose challenged. Serum glucose level was measured using the glucose oxidase method, lipid profile (total cholesterol, triglyceride, HDL cholesterol) was measured using an enzymatic-colorimetric method and LDL cholesterol was calculated using the formula: LDL cholesterol= total cholesterol-(HDL cholesterol + triglyceride/5). Glycosylated hemoglobin (HbA1c) was measured using turbidimetric inhibition immunoassay (Dimension clinical chemistry system). 
Electrolytes such as, $\mathrm{Na}^{+}, \mathrm{K}^{+}, \mathrm{Cl}^{-}$and $\mathrm{HCO}_{3}{ }^{-}$were measured by Selective Ion Electrodes (Biolyte 2000 automate analyzer).

\section{Statistical analysis}

Statistical analysis was performed using SPSS (Statistical Package for Social Program) software for Windows version 12 (SPSS Inc. Chicago. Illinois, USA). All data were expressed as mean SD (standard deviation), median, and/or percentage (\%) as appropriate. The statistical significance of differentials between the values was assessed by ANOVA or MannWhitney U test (as appropriate).

\section{RESULTS}

\section{Anthropometric and clinical status of the study subjects}

Age, systolic blood pressure, diastolic blood pressure, serum creatinine, and SGPT were significantly higher in type 2 diabetic subjects without retinopathy (DWR) and type 2 diabetic retinopathy (DR) subjects compared to that in controls (Table 1). Waist to Hip ratio (WHR) was significantly higher in DWR and significantly lower in DR subjects compared to the control group. BMI was significantly higher in DR compared to control, but did not show any difference between DWR and controls. Fasting glucose and postprandial glucose (after $2 \mathrm{~h}$ glucose challenged) were significantly higher in DWR and DR compared to Control. Glycosylated hemoglobin (HbA1c) was significantly higher in DWR and DR compared to control group.

\section{Lipids level of the study subjects}

Total cholesterol, high-density lipoprotein cholesterol (HDL-c), low-density lipoprotein cholesterol (LDL-c) were significantly higher in both DWR and DR groups compared to the controls. Triglyceride was significantly higher in the DR group, but no difference was found in DWR compared to the control group (Table 2).

\section{Electrolytes status of the study subjects}

The electrolytes of sodium ion $\left(\mathrm{Na}^{+}\right)$were significantly lower in the DR group but no difference was found in DWR compared to the control group but potassium ion $\left(\mathrm{K}^{+}\right)$was significantly higher in both DWR and DR groups compared to the control group (Table 3). In the case of chloride ion $\left(\mathrm{Cl}^{-}\right)$was significantly higher in DWR compared to controls whereas DR subjects were significantly lower compared to controls. Bicarbonate $\left(\mathrm{HCO}_{3}^{-}\right)$showed no difference between DWR and control group but DR was significantly lower compared to than in controls.

\section{Correlation analyses}

In diabetic retinopathy (DR) group $\mathrm{HbA1c}$ showed positive correlation with fasting serum glucose $(\mathrm{p}<0.001), 2 \mathrm{~h}$ postprandial serum glucose $(\mathrm{p}<0.001), \mathrm{HCO}_{3}^{-}(\mathrm{p}<0.016)$. Whereas, in diabetic without retinopathy (DWR) group HbA1c showed a positive correlation with fasting serum glucose $(\mathrm{p}<0.001), 2 \mathrm{~h}$ postprandial serum glucose $(\mathrm{p}<0.001)$

\section{DISCUSSION}

Diabetic retinopathy caused by complications of diabetes mellitus and is the fifth-leading cause of global blindness. It is an ocular manifestation of systemic disease which affects up $80 \%$ of all patients who have had diabetes. In Bangladesh, approximately $6.1 \%$ of the population aged 20-79 years have diabetes and 1.54 million people with DR. Serum lipids claimed to play an important role in the development and progression of DR that has been evaluated worldwide with different studies ${ }^{14,15}$. This study was aimed to find the association of lipids and electrolytes with DR in Bangladeshi Type 2 DM subjects.

In the current study, higher LDL, Cholesterol ,TG and lower HDL were found in both DWR and DR group compared to control (Table 2). Elevated levels of VLDL-cholesterol, LDL- cholesterol, triglycerides and low levels of HDLcholesterol is a common problem for patients with diabetes ${ }^{22}$. Several studies have reported the association of lipids with DR, but the results have not been consistent. Verges (2015) found a significant association between elevated serum total cholesterol and LDL-cholesterol with the severity of retinal hard exudation in patients with $\mathrm{DR}^{23}$. Chennai Urban Rural Epidemiology Study (CURES), showed that the mean serum TC, TG and non HDL-C levels were higher in patients with $\mathrm{DR}$ as compared to those without $\mathrm{DR}^{24}$. 
In our study, the mean TG level in diabetic with retinopathy was higher than in diabetes without retinopathy and it was statistically significant $(\mathrm{p}<0.001)$. From the results, it can be predicted that higher levels of TG indicate risk for the development of retinopathy in diabetes. The result was consistent with previous reports found significantly higher TG levels compared to healthy control.TG was found higher only in the DR group compared to control that indicates it plays a major role in the development of retinopathy in diabetic subjects which is similar to the findings of other studies ${ }^{14,15}$. Increased plasma levels of triglycerides in VLDL are known as common characteristics of dyslipidemia associated with type 2 diabetes ${ }^{25}$. The possible mechanism is the reduced action of insulin on adipocytes. It reduces the suppression of the hormone-sensitive lipase action on the stored TG, thus releasing large amounts of free fatty acids. Delivery of the released fatty acids to the liver increases the hepatic TG production and subsequently increased production and release of $\mathrm{VLDL}^{26}$. HbA1c indicates the glycemic control of diabetic subjects. The mean HbA1c level of DR group was $11.80 \pm 1.63$. Hyperlipidemia was evident in the poor glycemic controlled DR and DWR group. The dyslipidemia was characterized by elevated total serum cholesterol, triglyceride, LDL-cholesterol. Hepatic production of VLDL is known to be suppressed by insulin, and thus lack of insulin action would promote its production ${ }^{27}$.

The measurement of TG shows the possibility of being a successful approach to the monitoring of diabetic patients ${ }^{28}$. Individuals with elevated total serum cholesterol, low-density lipoprotein (LDL) cholesterol or triglyceride levels are more likely to have or develop retinal hard exudates, which can be associated with risk of vision loss, independent of the extent of macular oedema ${ }^{29}$. The progression to proliferative retinopathy was also shown to be related to serum triglycerides. Findings of a Study Group have been shown that cholesterol is related to all levels of retinopathy and triglycerides are associated with moderately severe non-proliferative and proliferative retinopathy ${ }^{30}$.

In this study, serum Na+ level decreased sequentially in DWR and DR groups compared to the control group which was in line with Mirsamadi et. al. $(2004)^{31} . \mathrm{K}^{+}$and $\mathrm{Cl}$ - were significantly higher in diabetic without retinopathy than the control group that is opposite to the finding reported by the study in the Nigerian population ${ }^{33}$. In diabetic retinopathy group, levels of $\mathrm{Na}+, \mathrm{Cl}-$ and $\mathrm{HCO}_{3}^{-}$were lower than the control group. Clayton et. al. studies reported significant differences between serum $\mathrm{Na}+$ of those suffering from age-related cataract ${ }^{32}$. Significantly lower serum potassium in diabetics than in the control is in contrast with the role of blood glucose in potassium metabolism (high serum glucose enhances the movement of potassium from the extracellular fluid into the cells) that is evidenced by significantly lower serum $\mathrm{K}^{+}$in diabetics with poor glucose level. Both elevated and reduced serum $\mathrm{K}^{+}$have been found to have a profound effect on neurotransmission as well as cardiac functions ${ }^{33}$. Intracellular dehydration is associated with a shift of potassium out of cells into the extracellular space. Potassium shifts are further enhanced by the presence of acidosis and the breakdown of intracellular protein secondary to insulin deficiency. Moreover, insulin deficiency prevents re-entry of $\mathrm{K}^{+}$into the cells. Osmotic diuresis and ketonuria lead to an increase in $\mathrm{K}^{+}$loss in urine. This pattern of electrolyte disturbances is remarkably similar to that previously observed in people with diabetes mellitus ${ }^{34}$. In this study, severely elevated serum potassium with moderate sodium decrease was observed in the DR group which was consistent with the findings of Javaid et al $(2007)^{20}$. In correlation analysis, HbA1c showed a significant positive correlation with BMI, Creatinine, and $\mathrm{HCO}_{3}{ }^{-}$.

Conclusion: Cholesterol, TG, and LDL-C level seems to be positively associated with DR. However, HDL was negatively associated with DR. Electrolyte $\mathrm{K}^{+}$ion was positively associated with Diabetic retinopathy but $\mathrm{Na}^{+}, \mathrm{Cl}^{-}$, $\mathrm{HCO}_{3}{ }^{-}$electrolytes showed inverse association with DR. The result indicates that dyslipidemia and electrolyte imbalance are risk factors in diabetic retinopathy patients.

Table 1. Anthropometries and Clinical characteristics of the study subjects

\begin{tabular}{|l|c|c|c|}
\hline \multicolumn{1}{|c|}{ Variables } & Control group & $\begin{array}{c}\text { Diabetic without } \\
\text { retinopathy (DWR) } \\
\mathrm{n}=80\end{array}$ & $\begin{array}{c}\text { Diabetic retinopathy } \\
\text { (DR) } \\
\mathrm{n}=63\end{array}$ \\
\hline Age $($ Year) & $45.88 \pm 7.52$ & $49.78 \pm 8.36$ & $53.75 \pm 8.14$ \\
\hline BMI $\left(\mathrm{Kg} / \mathrm{m}^{2}\right)$ & $23.59 \pm 1.82$ & $24.15 \pm 3.36$ & $25.21 \pm 3.28^{*}$ \\
\hline WHR & $0.93 \pm 0.03$ & $0.92 \pm 0.04^{*}$ & $0.94 \pm .01^{*}$ \\
\hline S_BP $(\mathrm{mm} \mathrm{Hg})$ & $118.80 \pm 7.71$ & $128.18 \pm 10.28^{*}$ & $150.79 \pm 10.12^{*}$ \\
\hline D_BP $(\mathrm{mm} \mathrm{Hg)}$ & $77.66 \pm 5.15$ & $86.75 \pm 8.96^{*}$ & $91.26 \pm 9.20^{*}$ \\
\hline S_GPT (U/L) & $33.54 \pm 2.2$ & $26.17 \pm 8.71^{*}$ & $29.91 \pm 7.86^{*}$ \\
\hline S_Crea (U/L) & $0.71 \pm 0.14$ & $1.04 \pm 0.32^{*}$ & $1.36 \pm 0.24^{*}$ \\
\hline HbA1c $(\%)$ & $5.45 \pm 0.35$ & $8.60 \pm 1.17^{*}$ & $11.80 \pm 1.63^{*}$ \\
\hline F_Glu (mmol/L) & $5.07 \pm 0.51$ & $8.00 \pm 1.27^{*}$ & $12.06 \pm 1.61^{*}$ \\
\hline 2h_Glu(mmol/L) & $6.9 \pm 0.72$ & $13.56 \pm 2.76^{*}$ & $19.83 \pm 4.83^{*}$ \\
\hline
\end{tabular}


Results were expressed as Mean \pm SD. Differences among the groups were calculated using ANOVA (Bonferroni ' $t$ ' test) in the significance at 5\% significance level $n=$ number of subjects, BMI= Body mass index, WHR= Waist Hip Ratio, S_BP= Systolic Blood Pressure, D_BP= Diastolic Blood Pressure, S_GPT= Serum GPT, SCrea= Serum Creatinine, F_Glu= Fasting Glucose and $2 \mathrm{~h} \_$Glu= After 2 hours Glucose. $\mathrm{p} \leq 0.05=$ significant.

Table 2: Lipid profile status of the study subjects

\begin{tabular}{|l|c|c|c|}
\hline Variables & $C=92$ & $D w r=80$ & $D r=63$ \\
\hline S_Cholesterol & $177.51 \pm 12.11$ & $195.40 \pm 41.64 * *$ & $221.46 \pm 22.42^{* *}$ \\
\hline HDL-C & $42.72 \pm 4.40$ & $35.54 \pm 5.04 * *$ & $31.60 \pm 3.49^{* *}$ \\
\hline LDL-C & $92.05 \pm 11.35$ & $127.98 \pm 42.39 * *$ & $142.33 \pm 20.72 * *$ \\
\hline Triglyceride & $187.13 \pm 27$ & $191.67 \pm 75.21$ & $307.46 \pm 55.96^{* *}$ \\
\hline
\end{tabular}

Results were expressed as Mean \pm SD. Differences among the groups were calculated using ANOVA (Bonferroni ' $t$ ' test) in the significance at $5 \%$ significance level $n=$ number of subjects, S_Cholesterol = Serum Cholesterol, HDL-c = High-Density Lipoprotein cholesterol, LDL-C=Low Density Lipoprotein. $\mathrm{p} \leq 0.05=$ significant.

\section{Table 3: Electrolytes status of the study subjects}

\begin{tabular}{|l|c|c|c|}
\hline Variables & $C=92$ & $D w r=80$ & $D r=63$ \\
\hline $\mathrm{Na}^{+}(\mathrm{mEq} / \mathrm{L})$ & $140.85 \pm 20.89$ & $139.33 \pm 12.02$ & $128.96 \pm 7.23^{*}$ \\
\hline $\mathrm{K}^{+}(\mathrm{mEq} / \mathrm{L})$ & $3.96 \pm 0.34$ & $4.18 \pm 0.50^{*}$ & $5.15 \pm 0.64^{*}$ \\
\hline $\mathrm{Cl}^{-}(\mathrm{mEq} / \mathrm{L})$ & $102.12 \pm 3.63$ & $103.43 \pm 5.45^{*}$ & $95.96 \pm 6.62^{*}$ \\
\hline $\mathrm{HCO}_{3}{ }^{-}(\mathrm{mEq} / \mathrm{L})$ & $24.92 \pm 2.27$ & $24.76 \pm 2.60$ & $22.63 \pm 2.56^{*}$ \\
\hline
\end{tabular}

Results were expressed as Mean \pm SD. Differences among the groups were calculated using ANOVA (Bonferroni ' $t$ ' test) in the significance at $5 \%$ significance level $\mathrm{n}=$ number of subjects, $\mathrm{Na}^{+}=$Sodium-ion, $\mathrm{K}^{+}=$Potassium ion, $\mathrm{Cl}^{-}=\mathrm{Cloride}$ ion, $\mathrm{HCO}_{3}{ }^{-}=$ Bicarbonate ion. $\mathrm{p}$-value was calculated using log-transformed value. $\mathrm{p}$ less or equal to $0.05=$ significant.

\section{Table 4: Correlation analyses for serum Na with different variables}

\begin{tabular}{|l|l|l|l|l|l|l|}
\hline \multicolumn{1}{|c|}{ Variables } & \multicolumn{2}{c|}{ Controls } & \multicolumn{2}{c|}{ DWR } & \multicolumn{2}{c|}{ DR } \\
\hline & $\mathrm{r}$ & $\mathrm{p}$ & $\mathrm{r}$ & $\mathrm{p}$ & $\mathrm{R}$ & $\mathrm{p}$ \\
\hline Age & -0.034 & 0.735 & -0.007 & 0.948 & -0.114 & 0.256 \\
\hline BMI & 0.111 & 0.271 & -0.046 & 0.650 & -0.010 & 0.922 \\
\hline WHR & 0.089 & 0.375 & -0.192 & 0.056 & -0.069 & 0.496 \\
\hline SBP & 0.172 & 0.085 & -0.052 & 0.609 & -0.217 & $\mathbf{0 . 0 2 9}$ \\
\hline DBP & -0.125 & 0.214 & 0.008 & 0.937 & -0.082 & 0.418 \\
\hline F_glu & -0.047 & 0.824 & -0.125 & 0.550 & -0.056 & 0.791 \\
\hline 2h_glu & -0.160 & 0.446 & -0.006 & 0.978 & 0.118 & 0.578 \\
\hline S_chol & 0.328 & $\mathbf{0 . 0 0 1}$ & 0.093 & 0.357 & 0.041 & 0.687 \\
\hline HDL & -0.024 & 0.812 & 0.173 & 0.085 & 0.046 & 0.650 \\
\hline LDL & 0.175 & 0.081 & 0.039 & 0.702 & 0.019 & 0.851 \\
\hline TG & 0.007 & 0.946 & 0.009 & 0.933 & -0.016 & 0.847 \\
\hline HBA1c & -0.091 & 0.367 & -0.007 & 0.942 & -0.044 & 0.663 \\
\hline S_creat & 0.082 & 0.416 & -0.203 & $\mathbf{0 . 0 4 3}$ & -0.043 & 0.673 \\
\hline SGPT & 0.046 & 0.648 & 0.051 & 0.617 & -0.039 & 0.698 \\
\hline K & 0.174 & 0.082 & -0.211 & $\mathbf{0 . 0 3 5}$ & 0.000 & 0.999 \\
\hline Cl & -0.119 & 0.237 & 0.614 & $<\mathbf{0 . 0 0 1}$ & 0.390 & $<\mathbf{0 . 0 0 1}$ \\
\hline HCO3 & -0.109 & 0.280 & 0.182 & 0.071 & 0.035 & 0.730 \\
\hline Duration & 0.00 & 0.00 & -0.105 & 0.296 & 0.051 & 0.611 \\
\hline
\end{tabular}

Results were expressed as correlation coefficient (spearmans rho) $\mathrm{r}$ values. BMI= Body mass index, WHR= Waist Hip Ratio, S_BP= Systolic Blood Pressure, D_BP= Diastolic Blood Pressure, S_GPT= Serum GPT, SCrea= Serum Creatinine, F_Glu= Fasting Glucose and 2h_Glu= After 2 hours Glucose, S_Cholesterol = Serum Cholesterol, HDL-c = High Density Lipoprotein cholesterol, LDL$\mathrm{C}=$ Low Density Lipoprotein, HbA1c= Glycosylated hemoglobin 
Table 5: Correlation analyses for serum $\mathrm{K}$ with different variables

\begin{tabular}{|c|c|c|c|c|c|c|}
\hline \multirow[t]{2}{*}{ Variables } & \multicolumn{2}{|c|}{ Controls } & \multicolumn{2}{|c|}{ DWR } & \multicolumn{2}{|c|}{ DR } \\
\hline & $\mathrm{r}$ & $\mathrm{p}$ & $\mathrm{r}$ & $\mathrm{p}$ & $\mathrm{r}$ & $\mathrm{p}$ \\
\hline Age & 0.045 & 0.656 & -0.029 & 0.777 & -0.020 & 0.839 \\
\hline BMI & 0.079 & 0.430 & 0.248 & 0.013 & 0.109 & 0.276 \\
\hline WHR & 0.031 & 0.761 & 0.204 & 0.041 & 0.017 & 0.866 \\
\hline SBP & 0.190 & 0.057 & 0.248 & 0.013 & 0.077 & 0.443 \\
\hline DBP & 0.097 & 0.335 & 0.168 & 0.096 & 0.233 & 0.019 \\
\hline F_glu & -0.027 & 0.275 & 0.084 & 0.690 & 0.010 & 0.962 \\
\hline 2h_glu & -0.115 & 0.584 & -0.160 & 0.445 & -0.122 & 0.563 \\
\hline S_chol & 0.157 & 0.117 & -0.041 & 0.686 & 0.093 & 0.356 \\
\hline HDL & -0.086 & 0.394 & -0.044 & 0.664 & -0.117 & 0.242 \\
\hline LDL & 0.116 & 0.250 & -0.035 & 0.728 & 0.122 & 0.223 \\
\hline TG & -0.028 & 0.777 & 0.059 & 0.563 & 0.065 & 0.519 \\
\hline HBA1c & -0.071 & 0.481 & 0.080 & 0.428 & 0.152 & 0.130 \\
\hline S_creat & 0.098 & 0.333 & 0.131 & 0.195 & 0.097 & 0.336 \\
\hline SGPT & -0.099 & 0.323 & 0.048 & 0.636 & 0.127 & 0.209 \\
\hline $\mathrm{Na}$ & 0.174 & 0.082 & -0.211 & 0.035 & $<0.001$ & 0.999 \\
\hline $\mathrm{Cl}$ & 0.010 & 0.923 & -0.179 & 0.074 & -0.028 & 0.785 \\
\hline $\mathrm{HCO} 3$ & 0.085 & 0.396 & 0.048 & 0.637 & 0.108 & 0.283 \\
\hline Duration & - & - & 0.147 & 0.146 & -0.026 & 0.796 \\
\hline
\end{tabular}

Results were expressed as correlation coefficient (spearmans rho) $\mathrm{r}$ values. BMI= Body mass index, WHR= Waist Hip Ratio, $\mathrm{S} \_\mathrm{BP}=$ Systolic Blood Pressure, D_BP= Diastolic Blood Pressure, S_GPT= Serum GPT, SCrea= Serum Creatinine, F_Glu= Fasting Glucose and 2h_Glu= After 2 hours Glucose, S_Cholesterol = Serum Cholesterol, HDL-c $=$ High Density Lipoprotein cholesterol, LDL$\mathrm{C}=$ Low Density Lipoprotein, HbA1c= Glycosylated hemoglobin

Table 6: Correlation analyses for serum HbA1c with different variables

\begin{tabular}{|c|c|c|c|c|c|c|}
\hline \multirow[t]{2}{*}{ Variables } & \multicolumn{2}{|c|}{ Controls } & \multicolumn{2}{|c|}{ DWR } & \multicolumn{2}{|c|}{ DR } \\
\hline & $\mathrm{r}$ & $\mathrm{p}$ & $\mathrm{r}$ & $\mathrm{p}$ & $\mathrm{R}$ & $\mathrm{p}$ \\
\hline Age & 0.069 & 0.496 & -0.086 & 0.393 & -0.064 & 0.525 \\
\hline BMI & 0.068 & 0.498 & 0.140 & 0.166 & 0.197 & 0.048 \\
\hline WHR & 0.106 & 0.291 & 0.033 & 0.741 & 0.003 & 0.976 \\
\hline SBP & 0.019 & 0.847 & 0.127 & 0.207 & -0.023 & 0.818 \\
\hline DBP & -0.070 & 0.488 & 0.165 & 0.100 & 0.024 & 0.810 \\
\hline F_glu & 0.981 & $<0.001$ & 0.659 & $<0.001$ & 0.672 & $<0.001$ \\
\hline 2h_glu & 0.722 & $<0.001$ & 0.525 & 0.007 & 0.617 & 0.001 \\
\hline S_chol & 0.120 & 0.233 & 0.039 & 0.700 & 0.036 & 0.722 \\
\hline HDL & 0.031 & 0.757 & -0.091 & 0.369 & 0.064 & 0.524 \\
\hline LDL & 0.012 & 0.908 & 0.074 & 0.466 & 0.098 & 0.322 \\
\hline $\mathrm{TG}$ & 0.128 & 0.203 & 0.012 & 0.903 & 0.064 & 0.525 \\
\hline S_creat & -0.005 & 0.959 & -0.155 & 0.124 & 0.220 & 0.027 \\
\hline SGPT & 0.056 & 0.580 & -0.004 & 0.969 & -0.026 & 0.797 \\
\hline $\mathrm{Na}$ & -0.091 & 0.387 & -0.007 & 0.942 & -0.044 & 0.663 \\
\hline $\mathrm{K}$ & -0.071 & 0.481 & 0.080 & 0.428 & 0.152 & 0.130 \\
\hline $\mathrm{Cl}$ & 0.123 & 0.221 & 0.055 & 0.587 & 0.035 & 0.725 \\
\hline $\mathrm{HCO} 3$ & 0.109 & 0.276 & -0.144 & 0.153 & 0.240 & 0.016 \\
\hline Duration & - & - & -0.008 & 0.936 & 0.248 & 0.012 \\
\hline
\end{tabular}

Results were expressed as correlation coefficient (spearmans rho) $\mathrm{r}$ values. BMI= Body mass index, WHR= Waist Hip Ratio, S_BP= Systolic Blood Pressure, D_BP= Diastolic Blood Pressure, S_GPT= Serum GPT, SCrea= Serum Creatinine, F_Glu= Fasting Glucose and 2h_Glu= After 2 hours Glucose, S_Cholesterol = Serum Cholesterol, HDL-c $=$ High Density Lipoprotein cholesterol, LDL$\mathrm{C}=$ Low Density Lipoprotein, HbA1c= Glycosylated hemoglobin 


\section{REFERENCES}

[1] Aiello, LP., Gardner, TW., King, GL., Blankenship, G., Cavallerano, JD., Ferris, FL., 3rd, et al. "Diabetic retinopathy", Diabetes Care, vol. 21, no. 1, pp. 143-56, 1998.

[2] Zélia Maria da, Silva Corrêa1, André Moraes, Freitas1 Italo and Mundialino Marcon, "Risk factors related to the severity of diabetic retinopathy", Arquivos Brasileiros de Oftalmologia, vol. 66 no. 6, pp. 739-743, 2003.

[3] Masoud R Manaviat, Mohammad Afkhami and Mohammad R Shoja, "Retinopathy and microalbuminuria in type II diabetic patients”, BMC Ophthalmology, vol. 4, no. 1, pp. 9, 2004.

[4] Araki, A., Ito, H., Hattori, A., Inoue, J., Sato, T., Shiraki, M., Orimo, H., "Risk factors for the development of retinopathy in elderly Japanese patients with diabetes mellitus”, Diabetes Care, vol.16, pp. 1184-6, 1993.

[5] Kalter-Leibovici, O., VanDyk, DJ., Leibovici, L., “ Risk factors for development of diabetic nephropathy and retinopathy in Jewish IDDM patients”, Diabetes, vol. 40, pp. 204-210, 1991.

[6] Kanski, J., "Diabetic Retinopathy" In: Kanski J. Clinical Ophthalmology, Oxford, Auckland: ButterworthHeinemann, pp. 344-57, 1994.

[7] Zhang, L., Krzentowski, G., Albert, A., "Lefebvre PJ. Risk of developing retinopathy in diabetes control and complications trial-type 1 diabetic patients with good or poor metabolic control", Diabetes Care, vol. 24, pp.1275-9, 2001.

[8] Okada, S., Ichiki, K, Tanokuchi, S., Hamada, H., Matsuo, N., Ota, Z., "Factors related to the development and progression of diabetic retinopathy in patients with type 2 diabetes", J Int Med Res, vol. 24, pp. 214-20, 1996.

[9] Dornan, TL., Carter, RD., Bron, AJ., Turner, RC., Mann, JI., "Low-density lipoprotein cholesterol: an association with the severity of diabetic retinopathy”, Diabetologia, vol. 22, pp. 167-70, 1982.

[10] Klein, BE., Klein, R., Moss, SE, "Is serum cholesterol associated with the progression of diabetic retinopathy or macular edema in persons with younger-onset diabetes of long duration"? Am J Ophthalmol, vol. 128, pp. 652-4, 1999.

[11] Cruickshanks, KJ., Ritter, LL., Klein, R., Moss, SE., "The association of microalbuminuria with diabetic retinopathy. The Wisconsin Epidemiologic Study of Diabetic Retinopathy. Ophthalmology", vol. 100 pp. 862 7, 1993.

[12] Engerman, RL., Kern, TS., "Progression of incipient diabetic retinopathy during good glycemic control" Diabetes, vol. 36, pp. 808-12, 1987.

[13] Rahman, MR., Arslan, MI., Hoque, MM., Mollah, FH., Shermin, S., "Serum lipids and diabetic retinopathy in newly diagnosed type 2 diabetic subjects" J Enam Med Coll, vol. 1 no. 2, pp 63-66, 2011.

[14] Gnaneswaran, S., Vinodhini, VM., Kuberan, D., Rajesh, K., Swamy, Raj SV., Kumar, JS,. "Dyslipidemia and Diabetic Retinopathy in a Rural Population” Int J Res Pharmaceut Biomed Sci., vol. 4, no. 3, pp. 829-832, 2013.

[15] Baynes, JW., Thorpe, SR., "Glycoxidation and lipoxidation in atherogenesis", Free Radic Biol Med, vol. 28, pp. 1708-16, 2000.

[16] Benarous, R., Sasongko, MB., Qureshi, S., Fenwick, E., Dirani, M., Wong, TY., et al. "Differential association of serum lipids with diabetic retinopathy and diabetic macular edema", Invest Ophthalmol Vis Sci, vol. 52, pp. 7464-9, 2011

[17] Ojiako, OA., Chikezie, PC., "Blood $\mathrm{Na} \pm / \mathrm{K} \pm$ and $\mathrm{Cl}$ levels of Hyperglycemic rats administered with traditional herbal formulations", Pharmacognosy Communications, vol. 5, no. 2, pp. 140-144, 2015. 
[18] Kitabchi, AE., Umpierrez, GE., Murphy, MB., Kreisberg, RA., "Hyperglycemic crisis in adult patients with diabetes: A consensus statement from the American diabetes association", Diabetes Care, vol. 29 pp. 2739$2748,2006$.

[19] Javaid, A., Hasan, R., Zaib, A., Mansoor, S., "A comparative study of the effects of hypoglycemic agents on serum electrolytes in diabetic patients", Pak J Pharm Sci., vol. 20, no. 1, pp. 67-71, 2007.

[20] Yasmin, F., Haleem, DJ., Haleem, MA., "Intraerythrocyte and serum electrolytes in diabetic patients with hypertension”, J Coll Physicians Surg Pak, vol. 16, no. 7, pp. 445-449, 2006.

[21] Haffner, SM., "Management of dyslipidemia in adults with diabetes", Diabetes Care, vol. 9, no. 1, pp. 1600 $1678,1998$.

[22] Yo-Chen Chang, Wen-Chuan Wu, "Dyslipidemia and Diabetic Retinopathy", The Review of Diabetic Studies, vol. 10, no. (2-3), 2013.

[23] Bruno Verges, "Pathophysiology of diabetic dyslipidemia: where are we?" Diabetologia, vol. 58, no. 5, pp. 886-899, 2015.

[24] Rema, M., Srivastava, BK., Anitha, B., Deepa, R., Mohan, V., "Association of serum lipids with diabetic retinopathy in urban South Indians - the Chennai Urban Rural Epidemiology Study (CURES) Eye Study—2", Diabetic Med. Vol. 23, no. 9, pp. 1029-1036, 2006.

[25] Valabhji, J. and Elkeles, RS, "Dyslipidemia in Type 2 Diabetes: Epidemiology and Biochemistry", The British Journal of Diabetes and Vascular Disease, vol. 3, pp. 184-189, 2003.

[26] Malmström, R., Packard CJ, Caslake, M., Bedford, D., Stewart, P., Yki-Järvinen, H., Shepherd, J., Taskinen, MR., "Defective regulation of triglyceride metabolism by insulin in the liver in NIDDM", Diabetologia, vol. 40, no. 4, pp. 454-62, 1997.

[27] Donnelly, CA., Seth, J., J, Seth., RM., Clayton, CI., Phillips, J., Cuthbert, RJ., Prescott, "Some blood plasma constituents correlate with human cataracts", British Journal of Ophthalmology, vol. 79, pp. 1036-1041, 1995.

[28] Chew, EY., Klein, ML., Ferris, FL., Remaley, NA., Murphy, RP., Chantry, K., Hoogwerf, BJ., Miller, D., "Association of elevated serum lipid levels with retinal hard exudate in diabetic retinopathy. Early Treatment Diabetic Retinopathy Study (ETDRS)”, Report 22, Arch Ophthalmol, vol. 114, no. 9, pp. 1079-84, 1996.

[29] Lloyd, CE., Klein, R., Maser, RE., Kuller, LH., Becker, DJ., Orchard, TJ., "The progression of retinopathy over 2 years: the Pittsburgh Epidemiology of Diabetes Complications (EDC) Study”, J Diabetes \& Its Complications, vol. 9 , pp. $140-8,1995$.

[30] Ishrat, Kareem, S.A. Jaweed, J.S. Bardapurkar, V.P. Patil, "Study of magnesium, glycosylated hemoglobin and lipid profile in diabetic retinopathy", Indian Journal of Clinical Biochemistry, vol. 19, no. 2, pp. 124-127, 2004.

[31] Mansour Mirsamadi, Issa Nourmohammadi, Manuchehr Imamian, "Comparative study of serum Na+ and K+ levels in senile cataract patients and normal individuals", Int J Med Sci., vol. 1, no. 3, pp. 165-9, 2004.

[32] Emmanuel Ugwuja and Eze MMLS, "Comparative study of serum electrolytes, total protein, calcium and phosphate among diabetic and HIV/AIDS patients in Abakaliki, Southeastern, Nigeria", The Internet Journal of Laboratory Medicine, vol. 2, no. 1, 2007.

[33] Clayton, RM., Cuthbert, J., Phillips, CI., Bartholomew, RS., Stokoe, NL., Fytch, T, et al., "Analysis of individual cataract patients and their lenses: A progress report", Experimental Eye Research, vol. 31, pp. 533$536,1980$.

[34] Sudhakar, K., Sujatha, M., Ramesh, Babu, S., Padmavthi, P., and Reddy PP., "Serum calcium levels in patients with essential hypertension and their first-degree relatives", Indian Journal of Clinical Biochemistry, vol. 9, no. 1 , pp. 1-23, 2004.

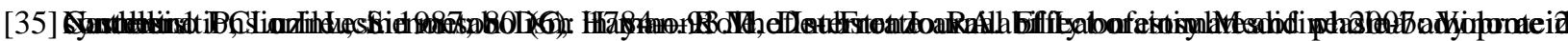

